\title{
Assessment and comparison of hygiene practices on complementary feeds among mothers in the urban and rural area in Thrissur district, Kerala
}

\author{
Babita Susan Kuruvilla ${ }^{1 *}$, Saju C.R ${ }^{2}$, Jenyz M Mundodan ${ }^{3}$, Jini M.P ${ }^{4}$ \\ ${ }^{1}$ RNTCP Medical Officer, ${ }^{2}$ Professor and Head, ${ }^{3}$ Assistant Professor, ${ }^{4}$ Lecturer and Statistician, ${ }^{2-4}$ Dept. of Community Medicine, \\ ${ }^{1}$ National Health Mission, Ernakulam, Kochi, Kerala, ${ }^{\mathbf{2}, 4}$ Amala Institute of Medical Sciences, Thrissur, Kerala, ${ }^{3}$ Government Medical \\ College, Idukki, Kerala, India
}

\section{Corresponding Author: Babita Susan Kuruvilla}

Email: drbabitasusan@gmail.com

\begin{abstract}
Introduction: Adequate Nutrition during infancy is required to ensure health, growth and development of children. Inappropriate feeding practices and infectious diseases are the main causes of malnutrition during the two years of life. The second half of an infant's first year is a vulnerable time, when breast milk alone cannot meet his/ her nutritional requirements and complementary feeding (CF) should be initiated. Safe preparation and hygiene practices are important determinants of proper CF practices.

Objective: To compare the hygiene practices related to complementary feeding among mothers in rural and urban areas in Thrissur district; and to determine the factors influencing this.

Materials and Methods: A comparative descriptive study was conducted among mothers of children in the age group of 1 to 2 years in the urban and rural field practice areas of Amala Institute of Medical Sciences, Thrissur from January 2016 to June 2017. House to house visits were done and data on hygiene practices related to complementary feeding was collected using pretested questionnaire through interview method.

Results: Before food preparation, 55\%and 22.8\% mothers in the urban and rural areas always wash their hands with soap. Before feeding, $45 \%$ mothers in the urban area always wash their hands with soap as compared to and $20(9.9 \%)$ in the rural area. The difference in the hygiene practices before food preparation, before and after feeding, use of boiled water and the use of separate utensils in the rural and urban area was found to be statistically significant $(\mathrm{P}=0.001)$. There is significant statistical difference between mothers' education, socioeconomic status and hygiene practices.
\end{abstract}

Conclusion: Hygiene practices in the urban area were generally more satisfactory than in the rural areas.

Keywords: Complementary feeding, Hygiene practices, Infant and young child feeding, Urban, Rural.

\section{Introduction}

Optimal IYCF (Infant and Young Child Feeding) practices is fundamental to a child's growth and development. ${ }^{1}$ Moreover, adopting proper feeding practices can reduce childhood morbidity and mortality. ${ }^{2}$ It is well known that the period from birth to two years of age is crucial for promotion of proper growth, behavioural and cognitive development. Therefore this period is also called "critical window". Various studies have suggested that it is the period for growth faltering, micronutrient deficiencies and also diarrhoea. Timely introduction and appropriate feeding practices is essential to building good nutritional status in infants and young children. ${ }^{4}$ However, complementary feeds that are nutritionally not adequate and microbiologically unsafe increase the risk of multiple nutrient deficiencies and gastrointestinal illnesses. Safe hygiene practices include the following: Those who handle food, during preparation, after feeding need to thoroughly wash their hands with soap and water. This hand hygiene practice need to be practised after defecation also. ${ }^{5}$ Kitchen utensils and cooking surfaces must be kept neat and clean. In a study done in the urban area of Uttar Pradesh, hand washing with soap prior to food preparation, before and after feeding was done by $59.5 \%$ and $59.3 \%$ mothers respectively. Eighty four percentage mothers washed their hands with soap after defecation. ${ }^{6}$ Some studies on this aspect have been done in India but only a few studies comparing the hygiene practices in the urban and rural setting have been done so far. For the afore mentioned reasons, study was done to assess and compare hygiene practices related to complementary feeding among mothers in the urban and rural setting of Thrissur district in Kerala.

\section{Materials and Method}

A comparative study which was descriptive in nature was carried out in the field practice areas of Rural Health Centre (RHC), Kallur and Urban Health Centre (UHC), Patturaickal of Amala Institute of Medical Science (AIMS), Thrissur. This study was conducted over a time period of 18 months. To study the feeding practice areas during 6-12 months, children between 12 months to 23 months were taken. Mothers in the above mentioned areas with children between 12 months and 23 months were included in the study and mothers who have been advised against breast feeding due to any medical condition for the mother and/or child were excluded. A comparative descriptive study done by Ashwini. S.et al showed that the complementary feeding rates in the urban area of Karnataka to be $42.1 \%$ and its rural area to be $28.8 \%$. $^{7}$ The sample size in this study was calculated to be 202 in the urban and rural area based on the above mentioned study.

There were 772 children in the age group of one to two years in the urban field practice area as per the list obtained from anganwadi workers. For selection of houses for survey, systematic random sampling technique was applied. A house to house survey was done and data regarding 
complementary feeding and related hygiene practices was collected by interviewing the subjects with a pretested questionnaire. Criteria for hygiene practices were based on the following questions. 1) Washing with soap before food preparation 2) Washing with soap before feeding 3) Washing with soap after feeding 4) Washing with soap after defecation 5) Use of separate considered to have good hygiene practice and rest were considered to have bad hygiene practice. Data was entered in Excel sheet after coding. SPSS version 23.0 software was used for analysis of the data. Ethical clearance was obtained from the Institutional Review Board of Amala Institute of Medical
Sciences (AIMS). Informed consent was taken from the participants.

\section{Results}

Field practice areas of Rural Health Centre (RHC), Kallur and Urban Health Centre (UHC), Patturaikkal of AIMS were the study centres chosen. Complementary feeding rate initiation at six months of age were $71.2 \%$ in the urban area and $66.8 \%$ in the rural area. $62.5 \%$ children were given mashed rice as the first weaning food in the urban area whereas $64.5 \%$ children were given ragi as the initial weaning food in the rural area.

Table 1: Distribution of study subjects according to Hygiene practices - Part I

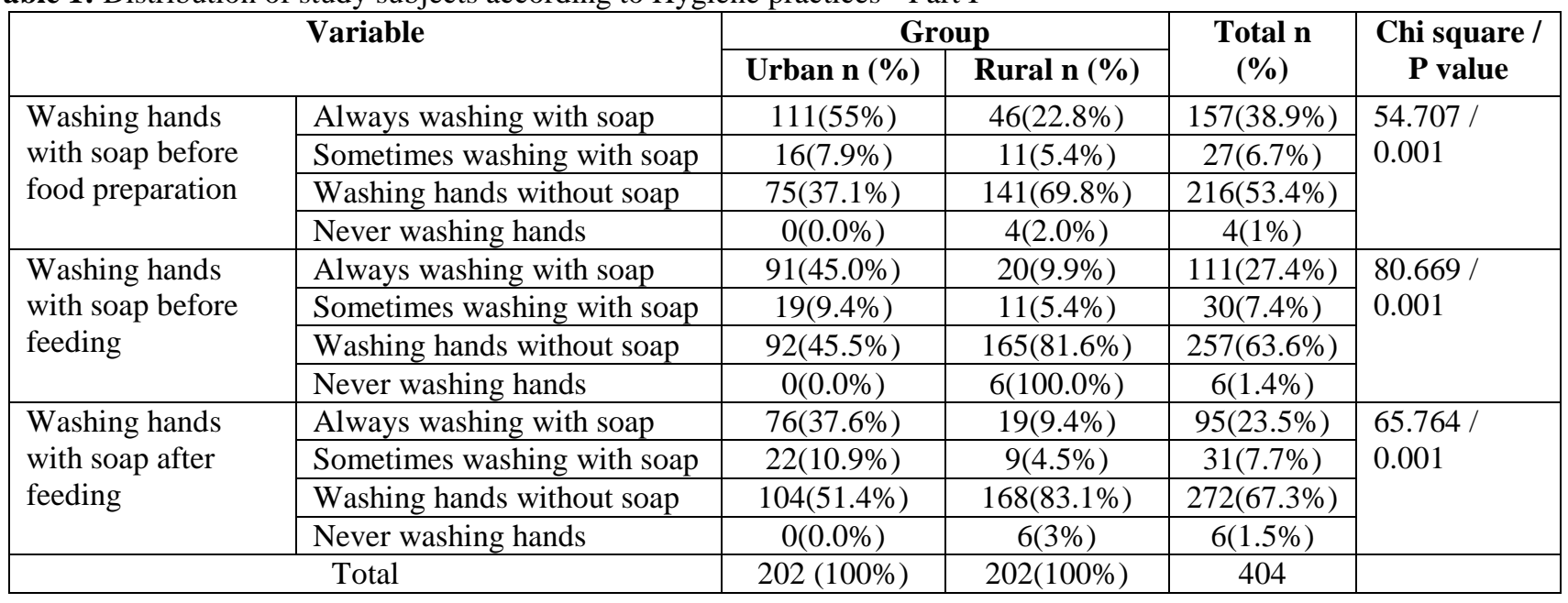

Table 2: Distribution of study subjects according to Hygiene practices - Part II

\begin{tabular}{|c|c|c|c|c|c|}
\hline \multicolumn{2}{|r|}{ Variable } & \multicolumn{2}{|c|}{ Group } & \multirow[t]{2}{*}{ Total n (\%) } & \multirow{2}{*}{$\begin{array}{c}\text { Chi square } \\
\text { / P value }\end{array}$} \\
\hline & & Urban n (\%) & Rural n (\%) & & \\
\hline \multirow{3}{*}{$\begin{array}{l}\text { Washing hands } \\
\text { after defecation }\end{array}$} & Always washing with soap & $201(99.5 \%)$ & $195(96.5 \%)$ & $396(98.0 \%)$ & \multirow{3}{*}{$\begin{array}{c}8.409 / \\
0.015\end{array}$} \\
\hline & Sometimes washing with soap & $1(0.5 \%)$ & $1(0.5 \%)$ & $2(0.5 \%)$ & \\
\hline & washing hands without soap & $0(0.0 \%)$ & $6(3.0 \%)$ & $6(1.5 \%)$ & \\
\hline \multirow{3}{*}{$\begin{array}{l}\text { Using separate } \\
\text { utensils }\end{array}$} & Always & $189(93.5 \%)$ & $165(81.6 \%)$ & $354(87.6 \%)$ & \multirow{3}{*}{$\begin{array}{c}13.640 / \\
0.001\end{array}$} \\
\hline & Sometimes & $8(3.9 \%)$ & $18(8.9 \%)$ & $26(6.4 \%)$ & \\
\hline & Never & $5(2.4 \%)$ & $19(9.4 \%)$ & $24(5.9 \%)$ & \\
\hline \multirow{3}{*}{$\begin{array}{l}\text { Use of boiling } \\
\text { water }\end{array}$} & Always & $200(99.0 \%)$ & $172(85.1 \%)$ & $372(92.1 \%)$ & \multirow{3}{*}{$\begin{array}{c}32.703 / \\
0.001\end{array}$} \\
\hline & Sometimes & $2(0.1 \%)$ & $22(10.9 \%)$ & $24(5.9 \%)$ & \\
\hline & Never & $0(0.0 \%)$ & $8(3.9 \%)$ & $8(2.0 \%)$ & \\
\hline & Total & $202(100 \%)$ & $202(100 \%)$ & 404 & \\
\hline
\end{tabular}

Table 3: Factors influencing complementary feeding practice

\begin{tabular}{|c|c|c|c|c|c|}
\hline \multirow{2}{*}{\multicolumn{2}{|c|}{ Variables }} & \multicolumn{2}{|c|}{ Hygiene Practice } & \multirow{2}{*}{ Total } & \multirow{2}{*}{$P$ value } \\
\hline & & Satisfactory & Unsatisfactory & & \\
\hline \multirow[t]{4}{*}{ Mother's age } & $20-25$ & $10(14.7 \%)$ & $68(87.35)$ & 78 & \multirow[t]{4}{*}{0.256} \\
\hline & $26-30$ & $29(16.0 \%)$ & $152(84.0 \%)$ & 181 & \\
\hline & $31-35$ & $26(23.4 \%)$ & $85(76.6 \%)$ & 111 & \\
\hline & 36 and above & $6(17.6 \%)$ & $28(82.4 \%)$ & 34 & \\
\hline \multirow{4}{*}{$\begin{array}{l}\text { Mother's } \\
\text { Education }\end{array}$} & Up to $7^{\text {th }}$ & $3(33.3 \%)$ & $6(66.7 \%)$ & 9 & \multirow[t]{4}{*}{0.017} \\
\hline & $7^{\text {th }}-10^{\text {th }}$ & $10(11.8 \%)$ & $75(88.2 \%)$ & 85 & \\
\hline & Pre-degree/ Higher Secondary & $11(10.9 \%)$ & $90(89.1 \%)$ & 101 & \\
\hline & Graduate / Postgraduate & $47(22.5 \%)$ & $162(77.5 \%)$ & 209 & \\
\hline Gender of the & Male & $38(18.4 \%)$ & $169(81.6 \%)$ & 207 & 0.671 \\
\hline
\end{tabular}




\begin{tabular}{|c|c|c|c|c|c|}
\hline child & Female & $33(16.8 \%)$ & $164(83.2 \%)$ & 197 & \\
\hline \multirow{3}{*}{ Birth order } & 1 & $39(17.6 \%)$ & $182(82.3 \%)$ & 221 & \\
\cline { 2 - 5 } & 2 & $29(17.8 \%)$ & $134(82.2 \%)$ & 163 & \\
\cline { 2 - 5 } & 3 & $2(11.1 \%)$ & $16(88.9 \%)$ & 18 & \\
\cline { 2 - 5 } & 4 & $1(50.0 \%)$ & $1(50.0 \%)$ & 2 & \\
\hline \multirow{4}{*}{ Religion } & Hindu & $41(16.2 \%)$ & $211(83.8 \%)$ & 252 & 0.060 \\
& Muslim & $3(8.1 \%)$ & $34(91.9 \%)$ & 37 & \\
\cline { 2 - 5 } & Christian & $27(23.5 \%)$ & $88(76.5 \%)$ & 115 & \\
\cline { 2 - 5 } Socioeconomic \\
\cline { 2 - 5 }
\end{tabular}

\section{Discussion}

\section{Hygiene Practices and factors influencing them}

Hand washing and use of soap: In the present study, 99\% mothers used to wash hands prior to food preparation as compared to $93.4 \%$ mothers in Ethiopia and $67 \%$ mothers in Dhaka, Bangladesh. Out of those, only 56(28.3\%) used soap for washing their hands in Ethiopia whereas in our current study, $39 \%$ use soap for washing prior to food preparation. ${ }^{8}$ This might be due to better literacy and cultural norms in our country

Hand washing after defecation: In a study done in Meerut in Uttar Pradesh, practice of washing hands with soap after defecation was done by $84.0 \%$ mothers ${ }^{6}$ whereas in our Kerala study, $96 \%$ mothers used to wash hands after defecation. This might be again due to our higher literacy rate

Use of separate utensils: One hundred and eighty nine (93.5\%) mothers in the urban area and $81.6 \%$ always use separate utensils for feeding the child compared to $32.3 \%$ in Ethiopia, $58 \%$ Nigeria and $75.5 \%$ Khartoum. ${ }^{9}$ This might be due to inadequate knowledge, low awareness and low socioeconomic status of the participants.

Use of boiled water: Two hundred (99.0\%) mothers in the urban area and $85.1 \%$ always use boiled water as compared to a study done in Uttar Pradesh, ${ }^{6} 15 \%$ mothers use boiled water to prepare baby food.

\section{Conclusion}

The results of comparative descriptive study points to the multifactorial determinants of complementary feeding practices in the urban and rural area. There is significant statistical difference between mothers' education, socioeconomic status and hygiene practices. Intense health education is needed to improve the complementary feeding practices and to inform the community about the timing, consistency, frequency and quality of complementary food items.

\section{Limitations}

Being a mere descriptive study, study subjects were interviewed only once and not followed up. Since the feeding practices were assessed during 6-12 months of age of the infants, there was a higher chance of recall bias. Mothers were more likely to give a socially desirable answers regarding hygiene practices i.e. social desirability bias.

\section{Acknowledgement}

The authors express their my sincere gratitude to the entire team of community medicine of Amala Institute of Medical Sciences for their support and timely advise. We also thank the anganwadi workers, ASHA and mothers of the children without whom study cannot be completed.

\section{Conflict of Interest: None.}

\section{References}

1. Ministry of Human Resource Development D of W and CF and NBG of I. National guidelines on infant and young child feeding. 2004.

2. Motee A, Ramasawmy D, Pugo-gunsam P, Jeewon R. An Assessment of the Breastfeeding Practices and Infant Feeding Pattern among Mothers in Mauritius. 2013;2013.

3. Nurliyana AR, Shariff ZM, Nasir M, Taib M, Gan WY, Tan K. Early nutrition, growth and cognitive development of infants from birth to 2 years in Malaysia: a study protocol. $B M C$ Pediatr [Internet]. 2016;1-7. Available from: http://dx.doi.org/10.1186/s12887-016-0700-0

4. Ahmad A, Madanijah S, Dwiriani CM, Kolopaking R. Complementary feeding practices and nutritional status of children 6-23 months old : formative study in Aceh , Indonesia. 2018;12(6):512-20.

5. Jacqueline K. Kung'u, Kathryn J. Boor, Shaali M. Ame, Nadra S. Ali, Anna E. Jackson and RJS. Bacterial Populations in Complementary Foods and Drinking-water in Households with Children Aged 10-15 Months in Zanzibar, Tanzania. J Heal Popul Nutr 2009;27(1):41-52.

6. Singhal P, Jain S. Infant and Young Child Feeding Practices with Special Reference to Complementary Feeding In an Urban Area of Meerut. IOSR J Humanit Soc Sci 2015;20(2):22-6.

7. Ashwini S, Katti SM, Mallapur MD. Comparison of complementary feeding practices among urban and rural mothers - A cross sectional study. Al Ameen J Med Sci 2014;7(4):257-64.

8. Living A, Children Y, Eastern N, Yitayih G, Belay K, Tsegaye M. Assessment of Hygienic Practice on Complementary Food among Mothers Assessment of Hygienic Practice on 
Complementary Food among Mothers with 6-24 Months Age Living Young Children in Mohoni Town , North Eastern Ethiopia , 2015. 2016;(October)

9. Is W, Monitoring F, Key-role-players WHOARETHE, Would

W, Monitoring F, Place T, et al. Kwazulu-Natal Food

Monitoring Protocol 2000

How to cite this article: Kuruvilla BS, Saju CR, Mundodan JM, Jini MP. Assessment and comparison of hygiene practices on complementary feeds among mothers in the urban and rural area in Thrissur district, Kerala. Indian $J$ Forensic Community Med 2019;6(2): 